\title{
MOTIVAÇÃO NO CONTROLE DO BIOFILME DENTAL E O APRENDIZADO EM RELAÇÃ̃ À SAÚDE BUCAL EM ESCOLARES
}

\section{MOTIVATION IN THE CONTROL OF DENTAL BIOFILM AND ORAL HEALTH LEARNING IN SCHOOL}

\author{
Márcia de Freitas Oliveira'; Sabrina Zanchett ${ }^{2}$; Roberto Luiz Evaristo Berndt ${ }^{3}$; \\ Marcus Vinícius Marques de Moraes $^{4}$ \\ ${ }^{1}$ Professora do Departamento de Odontologia, Fundação Universidade Regional de Blumenau. \\ E-mail: < marciaoliveira@furb.br> \\ ${ }^{2}$ Acadêmica do Curso de Odontologia Fundação Universidade Regional de Blumenau. E-mail: \\ <sabrinazan@hotmail.com> \\ ${ }^{3}$ Professor do Departamento de Odontologia, Fundação Universidade Regional de \\ Blumenau. E-mail: <robertoluiz.eb@terra.com.br> \\ ${ }^{4}$ Professor do Departamento de Fisioterapia, Fundação Universidade Regional de Blumenau. \\ E-mail: < moraes_33@hotmail.com>
}

Data de recebimento: $10 / 10 / 2012$

Data da aprovação: 05/12/2012

\section{RESUMO}

A escola é um ambiente propício para o desenvolvimento de programas de saúde e implementação de medidas preventivas, como hábitos de higiene bucal e dieta saudável. Dessa forma, o objetivo disse estudo foi avaliar a eficácia da estratégia motivacional em saúde bucal em escolares. Para isso foram avaliados o índice de higiene oral e o nível de conhecimento de saúde bucal de crianças regularmente matriculadas no Ensino Fundamental de uma escola pública no primeiro semestre de 2010. A população que foi estudada participou de seis sessões de motivação em saúde bucal, onde foram apresentadas palestras, desenhos, teatros, escovações que motivaram o autocuidado bucal. Os dados foram avaliados estatisticamente e pôde-se perceber que em relação à pergunta sobre o conhecimento da doença cárie notou-se o impacto positivo, o IHOS teve diferença estatisticamente significante após as sessões de motivação $(Z=-3,23$ e $\mathrm{p}=0,001)$. Concluiu-se que a estratégia de motivação aumentou o conhecimento de questões específicas em saúde bucal sendo que as questões de senso comum tiveram o seu efeito estável ou a resposta positiva com adesão aumentada e foi eficaz para reduzir o índice de placa.

Palavras chave: Educação em saúde. Pré-escolar. Índice de higiene oral. Motivação.

\begin{abstract}
Schools are suitable environments for the development of health programs and for the implementation of preventive measures such as oral hygiene and health diets. Thus, the aim of this study was to evaluate the effectiveness of a motivational strategy for the health education of preschool children. The study evaluated the oral hygiene and the level of knowledge of oral hygiene among children enrolled at an elementary public school in the first semester of 2010. The population studied attended 6 motivational sessions about oral hygiene in which they attended lectures, watched cartoons, theater plays and demonstrations on how to brush their teeth which motivated children's
\end{abstract}


oral self-care. The data was statically evaluated and it was possible to observe that knowledge about caries had a positive impact, the OHI-S had a statistically significant difference after the motivational sessions $(Z=-3.23, p=0.001)$. It was concluded that the motivational strategy increased the knowledge of specific issues about oral health and that the effect of common sense was either stabilized or had a positive response in addition to being effective in reducing the index of plaque.

Keywords: Health education. Preschool children. Oral hygiene index. Motivation.

\section{Introdução}

A cárie dentária e a doença periodontal são as doenças que mais acometem a cavidade bucal, sendo que a cárie é a doença mais comum nas crianças. Possui etiologia complexa e multifatorial, que inclui microbiota, dieta, hospedeiro, além de fatores coadjuvantes como socioeconômicos e ambientais. A doença cárie é resultado de um processo dinâmico que ocorre nos depósitos bacterianos (placa bacteriana na superfície dos dentes) que resulta, em seu processo final, na lesão de cárie. Se esse processo é interrompido, através da remoção da placa bacteriana, a lesão de cárie não se forma. Esta remoção de placa depende da motivação da pessoa de escovar os dentes e ter os cuidados básicos em relação a sua saúde bucal (FERREIRA et al., 2005; PAULETO; PEREIRA; CYRINO, 2004; THYLSLTRUP; FEJERSKOV, 1995).

Muitos são os programas de motivação e educação em relação à higiene bucal com métodos simples e eficientes para a remoção do biofilme dental e prevenção das doenças que ocasiona. A educação e motivação são capazes de despertar interesse pela manutenção da saúde, desenvolvendo nas pessoas consciência crítica das reais causas de seus problemas. Segundo a carta de Ottawa, a saúde se cria e se vive na vida cotidiana, nos centros de ensino, no trabalho e lazer. A saúde é resultado dos cuidados que se dispensa a si mesmo e aos demais, da capacidade de tomar decisões e controlar sua própria vida e de assegurar que a sociedade em que se vive ofereça a todos seus membros possibilidade de gozar de um bom estado de saúde (FERREIRA et al., 2005; TOASSI; PETRY, 2002)
A escola é um ambiente propício para o desenvolvimento de programas de saúde, pois reúne crianças em idades que favorecem a assimilação de medidas preventivas, como hábitos de higiene e dieta, que são formados na infância. A educação, por ser um instrumento de transformação social, propicia a reformulação de hábitos e a aceitação de novos valores, assim como a melhora na autoestima (ALVES; VOLSCHAN; HAAS, 2004; FERREIRA et al., 2005).

Colares e Feitosa (2003) avaliaram o desempenho na escola de crianças de 4 anos de idade portadoras de cárie severa através de um questionário que avaliava atenção em aula, realização de tarefas escolares e sua condição bucal. Concluíram que o desempenho de crianças portadoras de cárie severa na escola pode ser prejudicado por sua saúde bucal.

Toassi e Petry (2002) avaliaram a eficácia de duas estratégias motivacionais em relação ao controle do biofilme dental e sangramento gengival em 135 escolares. Em um dos grupos, a motivação foi feita em uma sessão única, e no outro a motivação foi realizada em quatro sessões. Notou-se uma redução altamente significante do índice de placa no grupo que recebeu motivação durante quatro sessões. Os autores concluíram que os reforços motivacionais em programas educativo-preventivos atuam positivamente para a redução do biofilme dental e sangramento gengival.

Aquilante et al. (2003) também avaliaram a eficácia de outro programa de prevenção em escolares pautado na verificação da performance de higiene do paciente através do índice PHP (componente psicomotor) e de uma entrevista baseada num questionário elaborado para avaliar os conhecimentos sobre saúde bucal (componente cognitivo). Após 
a jornada educativa, concluíram que os programas educativos promovem o aumento do conhecimento sobre saúde bucal e a redução do índice de placa. Observou-se ainda que, como é durante a infância que a criança vai incorporando em sua vida os hábitos de higiene e está numa fase propícia ao aprendizado, as pré-escolas são locais importantes para o desenvolvimento de Programas de Educação em Saúde Bucal.

Dessa forma, o trabalho educativo com escolares deve ser priorizado, pois é nessa época que os indivíduos estão mais aptos a aprender e adquirir hábitos de higiene oral e noções de conceitos em saúde bucal (MORANO JÚNIOR; MIALHE, 2008).

\section{Material e método}

A amostra foi composta por crianças regularmente matriculadas nas turmas de $2^{\mathrm{a}}$ a $5^{\mathrm{a}}$ séries do primeiro semestre de 2010. No Termo de Consentimento Livre e Esclarecido, foram solicitadas as assinaturas dos pais dos escolares que participaram da pesquisa (Anexo 1). Este trabalho foi aprovado pelo Comitê de Ética em Seres Humanos da Universidade Regional de Blumenau (FURB), sob protocolo número $233 / 09$.

Os materiais empregados na realização dos exames foram pastilhas evidenciadoras, espátulas de madeira, escovas dentais, creme dental, luvas, máscaras descartáveis, fichas clínicas e um questionário em que se verificou o conhecimento sobre saúde bucal dos envolvidos. O método foi constituído na evidenciação de placa bacteriana e anotação dos escores. Após o exame, os pré-escolares realizaram a escovação para remoção de placa e, em seguida, passaram por uma entrevista, quando responderam a um questionário sobre seus conhecimentos sobre saúde bucal.

Nas visitas semanais à escola, foram realizadas sessões de motivação pertinentes à saúde bucal a todas as crianças, com objetivo de orientá-las em relação aos cuidados com a sua própria boca. Os materiais didáticos utilizados para a motivação foram: macromodelos, fantoches, gincanas, cartazes e audiovisuais. Ao final da jornada educativa, que se constituiu de seis sessões de motivação em cuidado bucal, somente as crianças que participaram dos exames e entrevistas no início do experimento passaram novamente pelo levantamento do índice IHOS (Índice de
Higiene Oral) e pela entrevista para repetir o preenchimento do questionário. Nos levantamentos iniciais e finais, o experimento contou somente com dois examinadores calibrados para o índice IHOS.

A análise das variáveis categóricas provenientes dos questionários foi obtida através do teste do qui quadrado $\left(\mathrm{X}^{2}\right)$ com análise das tabelas de contingência. A análise do Índice de Higiene Oral antes e após as sessões de motivação foi realizada através do teste de Wilcoxon. Assumiu-se para as diferenças serem estatisticamente significativas o valor de $p<0,05$.

\section{Resultados}

Foram avaliadas as respostas dos questionários e o Índice de Higiene Oral de 59 crianças, sendo que 31 do gênero feminino e 28 do gênero masculino.

Em relação à pergunta sobre o conhecimento da doença cárie notou-se o impacto positivo das sessões de motivação sobre os escolares, pois houve uma mudança significativa nas respostas $\left(X^{2}=12,9\right.$ e $\mathrm{p}=0,01)$. Pode-se notar a diferença dos resultados nas figuras 1 e 2 :

Figura 1 - Conhecimento da cárie antes das palestras.

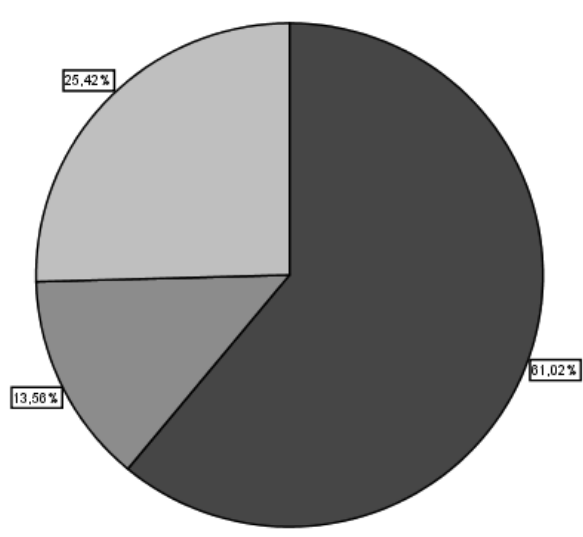

Conhecimento da "cárie" antes das palestras $\square$ Vaga idéia ㅁ Não sabe

Fonte: Dados da pesquisa, 2010. 
Figura 2 - Conhecimento da cárie após as palestras.

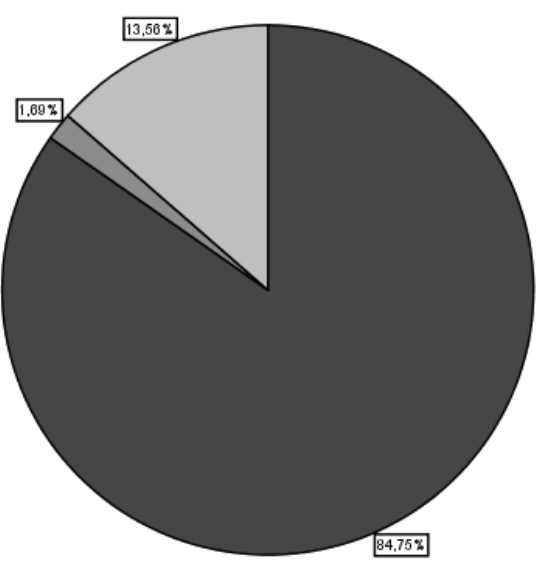

Fonte: Dados da pesquisa, 2010.

Já em relação à pergunta sobre o número de escovações, nos dois diferentes momentos de avaliação manteve-se a tendência da maioria dos alunos que escovam todos as vezes após se alimentarem ou pelo menos 3 vezes ao dia $\left(X^{2}=14,8\right.$ e $\left.p=0,53\right)$. As figuras 3 e 4 ilustram estes resultados.

Figura 3 - Número de escovações antes das palestras.

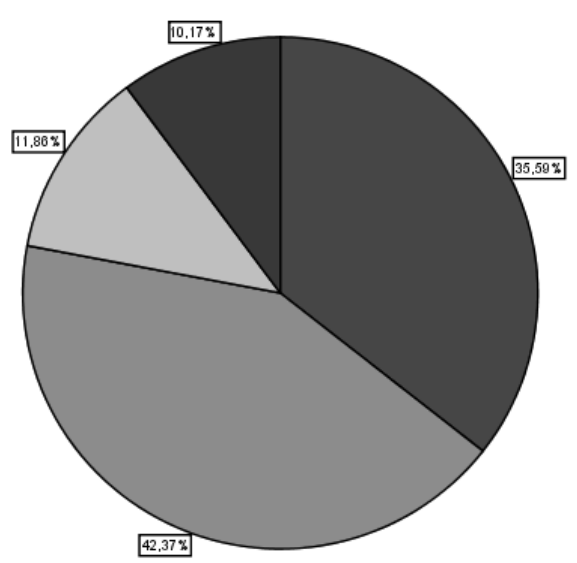

Número de escovações antes das palestras - Todas as vezes após

$\square$ vezes ao dia

ㄴ 2 vezes ao dia

Fonte: Dados da pesquisa, 2010.

Figura 4 - Número de escovações após as palestras.

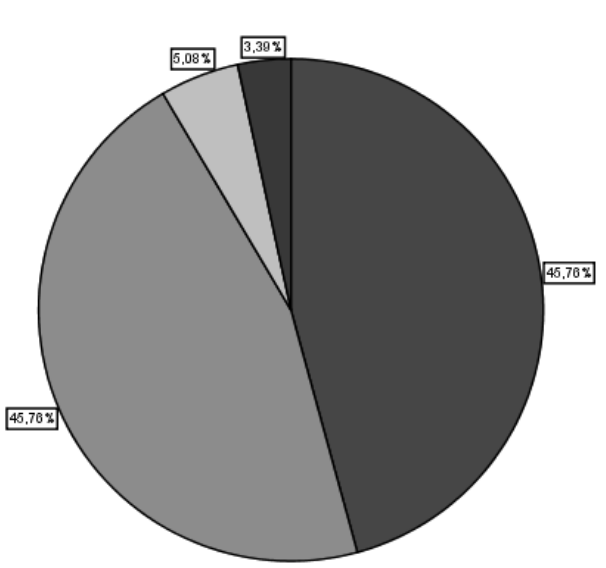

Número de escovações após palestras - Todas as vezes após

口 3 vezes ao dia ㄴ 2 vezes ao dia 1 vez do dia

Fonte: Dados da pesquisa, 2010.

O horário da escovação mais importante apontado pelos escolares antes das sessões de motivação foi a escovação noturna e após a ingestão de alimentos, dado que continuou ocorrendo após as semanas de motivações, sendo que houve uma migração de um maior número de respostas para a escovação noturna $\left(\mathrm{X}^{2}=10,71 \mathrm{e} \mathrm{p}=0,29\right)$.

A questão 4 , referente à aquisição de cuidados de higiene oral também não teve diferença estatisticamente significante $\left(X^{2}=0,131\right.$ e $\left.p=0,71\right)$, uma vez que os alunos já haviam tido orientações sobre higiene antes das sessões de motivação, sendo que adesão a resposta sim aumentou de $72,8 \%$ para $79,8 \%$.

A função do fio dental já era conhecida antes das sessões de motivação e não apresentou diferença estatisticamente significante $\left(\mathrm{X}^{2}=2,82\right.$ e $\left.\mathrm{p}=0,58\right)$. $\mathrm{O}$ fio dental passou a ser mais utilizado após as sessões de motivação, conforme se observa na sexta questão do questionário, em que a comparação entre os questionários apresentou-se estatisticamente significante $\left(X^{2}=13,15\right.$ e $\left.p<0,001\right)$.

As instruções durante as motivações foram impactantes para a melhora do entendimento sobre o flúor, pois houve diferença estatisticamente significante $\left(X^{2}=4,58\right.$ e $\left.p=0,032\right)$.

O IHOS teve diferença estatisticamente significante após as sessões de motivação $(Z=-3,23$ e $\mathrm{p}=0,001$ ).

Já a correlação da idade com o IHOS, após as sessões de motivação, apresentou-se menos 
significativa, induzindo que as crianças mais velhas têm menor índice de higiene oral, apresentando assim melhor higienização pois quanto menores os índices melhores são os hábitos de higiene oral.

\section{Discussão}

A motivação é um meio muito importante para promoção de saúde. Hoje existem vários métodos para que essa motivação ocorra, mas é necessário avaliar o quanto ele é eficaz. Portanto, uma alternativa viável para se obter melhor compreensão do paciente é a utilização de materiais simples e atrativos com conteúdos relacionados à sua rotina diária, sendo capazes de despertar a atenção e curiosidade das pessoas (BLINKHORN; VERITY, 1979; GARCIA et al., 2009).

Além disto, para que a educação e motivação produzam resultados desejados, o profissional deve utilizar métodos apropriados, compatíveis com o público alvo, principalmente quando se trabalha com a população infantil, que requer uma escolha mais cuidadosa (GARCIA; CORONA; VALSECKI, 1998; GARCIA et al., 2009).

Em relação ao nível de conhecimento em saúde bucal dos escolares da rede pública, é possível afirmar, através de resultados obtidos nos questionários, que os alunos tiveram um acréscimo no seu aprendizado quanto a questões específicas em odontologia, sendo que as questões de senso comum tiveram o seu efeito estável ou com a resposta positiva com adesão aumentada.

$\mathrm{Na}$ primeira abordagem do questionário sobre a pergunta "Você sabe o que é cárie?", muitos escolares responderam que não sabiam ou tinham uma vaga ideia; logo após as sessões de motivação, na segunda abordagem, a maioria dos escolares respondeu que sabia o que era a doença cárie.

Quando questionados sobre a frequência de escovação, não houve uma diferença nos dois momentos de avaliação, já que a maioria dos alunos respondeu que escova os dentes todas as vezes após se alimentar ou pelo menos 3 vezes ao dia, o que está de acordo com o trabalho realizado por Figueira e Leite (2008).

Sobre a escovação mais importante, no primeiro momento da pesquisa as respostas mais frequentes foram: a escovação noturna e após a ingestão de alimentos. No segundo momento da pesquisa manteve-se a frequência destas respostas, ocorrendo um acréscimo nas respostas para a escovação noturna.

O fio dental é o método de limpeza das superfícies proximais mais comumente recomendado. A sua função já era conhecida antes das sessões de motivação. O fio dental após as sessões de motivação passou a ser mais utilizado entre os escolares, tendo uma diferença estatisticamente significante entre a primeira e a segunda abordagem do questionário (MIYAZAKI; TAKUSHI; REICHE, 1997; MOHAMMED, 1965).

$\mathrm{Na}$ análise dos dados sobre a pergunta "sabe o que é flúor?", percebeu-se uma diferença significativa após a motivação, em que se mostrou um melhor entendimento sobre a importância do assunto, pois o flúor é um meio bastante eficaz na prevenção contra a cárie.

A diferença do IHOS no início e no final deste trabalho confirmou que os hábitos de higiene oral das crianças mudaram. Este achado está de acordo com os achados de outros autores que realizaram sessões de motivação em caráter semanal que também continham aulas demonstrativas as quais se mostraram mais eficientes para uma melhora da higiene oral (ALMEIDA; COUTO; GUSMÃO, 2001; TOASSI; PETRY, 2002).

Garcia et al (2009) perceberam uma redução significativa no índice de placa nos grupos de escolares nos quais foi aplicado um método de autoinstrução em higiene oral com diferentes enfoques. Os autores observaram uma maior redução no índice de placa do grupo em que as instruções foram realizadas e logo após foi feita uma discussão sobre o assunto. $\mathrm{O}$ presente estudo está de acordo com o trabalho dos autores citados, pois também foi encontrada uma redução do índice de placa mostrando que a motivação é um instrumento valioso para a uma boa higiene oral, a qual deve ser realizada de uma forma continuada para uma melhor efetividade.

Assim como Almeida, Couto e Gusmão (2001) e Toassi e Petry (2002) observaram a redução do IHOS após a motivação ter sido realizada de forma contínua. O presente trabalho também observou esta redução do IHOS após seis semanas de orientações para os escolares. No entanto, os autores citados não encontraram redução do índice de placa no grupo que participou de apenas uma aula demonstrativa. Os autores afirmaram que orientações de higiene oral, em 
períodos semanais, é a forma mais válida em função de melhorar o IHOS.

Este trabalho mostrou que o programa aplicado na escola, além de ter sido eficiente na melhora de higiene bucal de escolares, foi viável devido ao fato de ser simples, de fácil execução e de custo reduzido, o que está de acordo com Da Silva e Jorge (2000) que também citou este fato em sua pesquisa.

\section{Conclusões}

A estratégia de motivação aumentou o conhecimento de questões específicas em saúde bucal sendo que as questões de senso comum tiveram o seu efeito estável ou a resposta positiva com adesão aumentada

A estratégia de motivação em cuidado bucal utilizada foi eficaz para reduzir o índice de placa.

\section{Agradecimentos}

À FURB através do programa Pipe/Artigo 170 (Estado de Santa Catarina).

\section{REFERÊNCIAS}

ALMEIDA, J. C. S.; COUTO, G. B.; GUSMÃO, E. S. Escovação no controle da placa. avaliação do ensino e motivação em escolares. RGO, v. 49, n. 3, jul./set., 2001.

ALVES, M. U.; VOLSCHAN, B. C. G.; HAAS, N. A. T. Educação em saúde bucal: sensibilização dos pais das crianças atendidas na clínica integrada de duas universidades privadas. Pesq. Bras. Odontoped. Clin. Integr., João Pessoa, v. 4, n. 1, p. 47-51, jan./abr. 2004.

AQUILANTE, A. G. et al. A importância da educação em saúde bucal para pré-escolares. Revista de Odontologia da UNESP, v. 32, n. 1, p. 39-45, 2003.

BLINKHORN, A. S.; VERITY J. M. Assessment of the readability of dental health educati on literature. Community Dent Oral Epidemiol, v. 7, n. 4, p. 195-198, 1979.

CARTA DE OTTAWA. $1^{\circ}$ conferencia internacional sobre promoção de saúde. Ottawa, Canadá, Nov., 1986.

DA SILVA, C.P. M.; JORGE,A. O. C. Efeito de um programa educativo-preventivo na higiene bucal de escolares. Rev. Biociênc., Taubaté, v. 6, n. 2, p. 67-72, jul./dez., 2000.

FERREIRA, J. M. S.; MASSOI, A. C. L. T.; FORTE, F. D. S. F.; SAMPAIO, F. C. Conhecimento de alunos concluinte de pedagogia sobre saúde bucal. Comunic, Saúde, Educ., n. 17, p. 381-8, mar./ago., 2005.
FIGUEIRA, T. R; LEITE, I. C. G. Percepções, conhecimentos e práticas em saúde bucal de escolares. RGO. Porto Alegre, v. 56, n. 1, p. 27-32, jan./mar. 2008.

GARCIA P. P. N. S.; et al. Educação em saúde: efeito de um método de auto-instrução sobre os níveis de higiene oral em escolares. Pesq Bras Odontoped Clin Integr, João Pessoa, v. 9, n. 3, set./dez. 2009.

GARCIA, P. P. N. S.; CORONA, S. A. M.; VALSECKI, J. R. A. Educação e motivação I - impacto da efetividade de métodos educativos preventivos relativos à cárie dental $\mathrm{e}$ doença periodontal. Rev. Odontol. UNESP, v. 2, n. 27, p. 393-403, 1998.

KRAMER, P. F.; FELDENS, C. A.; ROMANO, A. R. Promoção de saúde bucal em odontopediatria: diagnóstico, prevenção e tratamento da cárie oclusal. São Paulo: Artes Médicas, 1997.

MIYAZAKI, A. Y.; TAKUSHI, F. J. A. R.; REICHE, M. Avaliação do nível de conhecimento e motivação relativo à saúde bucal em duas escolas de Londrina, Paraná. Semina, v.18, Ed. Especial, p. 83-9, 1997.

MOHAMMED, C. Dental removcú by 11 oss. J. New Jersey Dent. Soe., v.36, p. 419, 1965.

MORANO JUNIOR, M.; MIALHE, F. L. A importância da professora na promoção de saúde bucal dos escolares. Revista de Odontologia da Universidade Cidade de São Paulo, n. 20, v. 1, p. 19-22, 2008.

PAUleto, A. R.; PEREIRA, M. L. T.; CYRINO, E. G. Saúde bucal: uma revisão crítica sobre programação educativas para escolares. Ciência e Saúde Coletiva, v. 1, n. 9, p. 121-130, 2004.

THYLSTRUP, A., FERJESKOV, O. Cariologia clínica. São Paulo: Santos, 1995.

TOASSI, R. F. C.; PETRY, P. C. Motivação no controle do biofilme dental e sangramento gengival em escolares. Rev. Saúde Pública, v. 36, n. 5, p. 634-637, 2002. 